\title{
Prevalence of Urinary Incontinence in Women
}

\author{
LUBNA YASMIN ${ }^{1}$ FERDOUSI BEGUM²,
}

\begin{abstract}
:
Objective: The objectives of the study were to find out the prevalence of urinary incontinence in women.
\end{abstract}

Materials and Methods: A cross sectional study was conducted on five hundred one (501) women older than 18 years of age who were admitted in department of obstetrics and gynaecology of Shaheed Suhrawardi Medical College and Hospital from April to December 2009, answered a questionnaire about urinary incontinence. They were grouped according to presence or absence of urinary incontinence (incontinent and continent) and type of incontinence present (urge, stress and mixed).

Results: Urinary incontinence was found in 104(20.8\%) women, out of which 25 (24\%) suffered from stress incontinence only, 21 (20.2\%) suffered from urge incontinence and $58(55.8 \%)$ suffered mixed incontinence.

Conclusions: One in five women older than 18 years of age suffer from one or other form of urinary Incontinence.

Key word: Urinary Incontinence in female, Prevalence of Urinary Incontinence in woman

\section{Introduction:}

Incontinence is a prevalent health condition that is rarely discussed as people living in the condition are often embarrassed to discuss it with their health care providers. In fact the World Health Organization calls incontinence "one of the last medical taboos"1. Incontinence occurs in more than half of communitydwelling women 45 years old and older. Almost one of five women in the community reported urinary incontinence that affected normal activities ${ }^{2}$.

The bladder is the urine storage reservoir, the urethra is a passage through which the bladder is emptied and supportive structures, pelvic \& periurethral muscles are responsible for preventing leakage. Incontinence has been defined by the International Continence Society as the "complaint of any involuntary leakage of urine"3.

Compared with many other condition accurate statistics on the prevalence of incontinence are difficult to find out. One of the main reasons for this is the perceived social stigma associated with incontinence. Even people with symptoms of incontinence often will not admit to it, or seek treatment for it ${ }^{3}$.
The main types of incontinence include the followings Stress Urinary Incontinence (SUI), which is the leaking of urine with coughing, sneezing, straining, exercise or any other type of exertion ${ }^{1}$. Urge Incontinence (UI) is leaking of urine associated with the sudden uncontrollable urge to empty the bladder. The urge to empty the bladder cannot be delayed and leakage occurs. Over flow incontinence $(\mathrm{OI})$ is constant leaking or dribbling from a full bladder due to some neurological problem. Mixed incontinence $(\mathrm{MI})$ is a combination of stress and urge incontinence ${ }^{4}$.

True incontinence occurs where urine leaks through an injury or congenital anomaly in urethra or bladder. Urinary incontinence can be caused by weakening of the pelvic muscles and urethral muscles. It also occurs when a person cannot control the bladder muscles ${ }^{5}$.

There is hope on the horizon. The World Health Organization (WHO) has recently focused on the problem. At the first international WHO consultation on incontinence, in June, 1980, a committee of 24 members considered the best way to eradicate incontinence. The issue of cost and our poor

1. Jr. Consultant, OSD, DGHS, Mohakhali, Dhaka. E-mail: ylubna03@gmail.com, Mobile: 01711388688.

2. Professor, Department of Obstetrics and Gynaecology, Ibrahim Medical College and BIRDEM Hospital, Dhaka. Emai: fbegum9@gmail.com, Mobile: 01714008166

Address of Correspondence: Dr. Lubna Yasmin, MBBS, FCPS (Gynae \& Obs.), Jr. Consultant, OSD, DGHS, Mohakhali, Dhaka. E-mail: ylubna03@gmail.com, Mobile: 01711388688. 
knowledge of the magnitude of the problem was a major concern. The WHO concluded that incontinence should be considered a disease rather than a condition, in view of its debilitating effect upon health and wellbeing ${ }^{6}$.

The objective of the present study were to find out the prevalence of urinary incontinence among the women admitted in the Shaheed Suhrawardi Medical College \& Hospital Dhaka.

\section{Materials And Methods:}

A cross sectional study was conducted in the Department of Obstetrics and Gynaecology, Shaheed Suhrawardy Medical College and Hospital over a period of eight month from April 2009 to December 2009 on 501 consecutive subjects admitted in the department of Obstetrics and Gynaecology and fulfilling inclusion and exclusion criteria, Shaheed Suhrawardi Medical College and Hospital, Dhaka, Bangladesh from April 2009 to December 2009. Inclusion Criteria was women aged 18 years or more and exclusion criteria was patient admitted with emergency condition. Patients with true uncontenance were excluded at the beginning. The data for the study were collected through direct interviewing of the patient by using a structured questionnaire.

Informed verbal consent was obtained from all subjects. For each woman included in this study, data were collected by history taking, physical examination and relevant investigations. A woman was defined as having Urinary Incontinence (UI) symptoms if she responded "yes" to the following question: "Do you have urinary incontinence?" Data for all patients included in the cross-sectional study were gathered using a questionnaire.

Then further questions were asked to identify women with stress, urge, overflow or mixed incontinence.
Data entry \& analysis was performed using SPSS for Windows (version 16.0, Chicago, IL, USA). The collected data were checked edited \& entered and statistical analysis was done using appropriate statistical test. Unpaired't' test and chi (?2) square test were used to assess the significance of differences in categorical data. Differences was considered significant when $\mathrm{P}<0.05$.

\section{Results:}

Total numbers of study subjects were 501 . Out of them $104(20.8 \%)$ found to have urinary incontinence. The diagnosis of urinary incontinence was done by history and physical examination. Out of all subjects with urinary incontinence $25(24.0 \%)$ suffered from stress incontinence only, $21(20.2 \%)$ suffered from urge incontinence and 58 (55.8\%) suffered mixed incontinence (Table I).

Table I

Categorization of study subjects according to presence/ absence of urinary incontinence $(n=501)$

\begin{tabular}{lcc}
\hline Categorization & No. of subjects & Percentage \\
\hline Group I & 104 & 20.8 \\
$\quad$ Stress incontinence & 25 & 24.0 \\
Urge incontinence & 21 & 20.2 \\
$\quad$ Mixed incontinence & 58 & 55.8 \\
$\quad$ (Stress+Urge) & & \\
Group II & 397 & 79.2 \\
\hline
\end{tabular}

Group I= Urinary incontinence

Group II= No urinary incontinence

Table II shows that $50 \%$ menopausal ladies ( age $>50$ years) had statistically significantly higher frequency of urinary incontenance in comparison to those who were who were $\leq 50$ years of age $(12 \%)$.

Table-II

Distribution of the study subjects according to the age $(n=501)$

\begin{tabular}{|c|c|c|c|c|c|}
\hline \multirow[t]{2}{*}{ Age in year } & \multicolumn{2}{|c|}{ Group I $(n=104)$} & \multicolumn{2}{|c|}{ Group II $(n=397)$} & \multirow[t]{2}{*}{$P$ value } \\
\hline & $\mathrm{n}$ & $\%$ & $\mathrm{n}$ & $\%$ & \\
\hline$<20$ & 0 & 0.0 & 10 & 2.5 & \\
\hline $20-29$ & 0 & 0.0 & 79 & 19.9 & \\
\hline $30-39$ & 10 & 9.6 & 131 & 33.0 & \\
\hline $40-49$ & 35 & 33.7 & 117 & 29.5 & \\
\hline $50-59$ & 30 & 28.8 & 60 & 15.1 & \\
\hline$\geq 60$ & 29 & 27.9 & 0 & 0.0 & \\
\hline Mean $\pm S D$ & \multicolumn{2}{|c|}{$51.3 \pm 11.1$} & \multicolumn{2}{|c|}{$37.2 \pm 9.5$} & $<0.001^{\mathrm{s}}$ \\
\hline Range & \multicolumn{2}{|c|}{$(34-70)$} & \multicolumn{2}{|c|}{$(18-56)$} & \\
\hline
\end{tabular}

$S=$ Significant

$P$ value reached significant level from unpaired t-test 


\section{Discussion:}

This cross sectional study was carried out with an aim to find out the prevalence of urinary incontinence in women.

A total of 501 subjects ranging from 18 to 70 years were included in the study, who were admitted in the department of Obstetrics and Gynaecology, Shaheed Suhrawardy Medical College and Hospital, Dhaka, Bangladesh, during April 2009 to December 2009.

A total of 104 (20.8\%) subjects having urinary incontinence. Out of all subjects with urinary incontinence $25(24.0 \%)$ suffered from stress incontinence, $21(20.2 \%)$ suffered from urge incontinence and $58(55.8 \%)$ suffered mix incontinence. This closely resemble with the study of Yan-feng et al. ${ }^{7}$ where the authors found $19.0 \%$ had urinary incontinence. In other studies, the prevalence of urinary incontinence in the community ranged from 9.0 to $45.0 \% 8,9$.

Joao $L$ et $\mathrm{al}^{10}$ evaluated prevalence of fecal and urinary incontinence (UI) in Brazilian women. A total of 685 women were grouped according to presence or absence of UI. Urinary incontinence was reported in $27.0 \%$ of cases.

Lasserre et al $^{11}$ reported cross-sectional study of women aged $>18$ years was conducted by attending GPs between June 2007 and July 2007. Overall, 241 GPs enrolled 2183 women seen during $1 \mathrm{~d}$. The prevalence of UI was $26.8 \%$ ( $n=584$ ) Among women with UI, 496 were included in a cross-sectional survey: $45.2 \%(n=224)$ had stress UI, $42.1 \%(n=$ $209)$ had mixed UI, and $10.9 \%(n=53)$ had urge UI, while $2.0 \%(n=10)$ had UI of indeterminate type. Overall, 288 of 496 women(51.8\%) stated that UI had a negative impact on their QoL; this effect remained mostly mild or moderate, and only 197 of 496 women (39.7\%) had asked for medical help. Longer duration of symptoms, higher frequency of comorbid urinary symptoms, and altered QoL were most frequent among women with mixed UI $(p<0.001)$.

El-Azab et al. ${ }^{12}$ showed $46.0 \%$ urinary incontinence was found in grand multipara. Almost similar finding observed by Yan-feng ${ }^{13}$, which are consistent with the current study; the current study showed that $76.9 \%$ of urinary incontinence was found in grand multipara (para 4/more).

\section{Conclusion:}

One in five women older than 18 years of age suffer from one or other form of urinary Incontinence.

\section{Recommendation:}

Identification, Problem evaluation, early diagnosis is improvement for secondary prevention and improve the quality of life of Women suffering from urinary incontinence.

\section{Referance:}

1. Vestergom M. Incontinence: A Canadian Perspective. The Canadian Continence Foundation. Users/My\%20AsUs/Downloads/ Incontinence $\% 20-\% 20 \mathrm{~A} \% 20$ Canadian \%20Perspective\%20(1).pdf Downloaded on 22.3.2015

2. Swanson JG, Kaczorowski JS, Kelly J, Finkelstein M. Urinary Incontinence: A Common Problem Among Women over 45. Can Fam Physician. 2005;51(1):85.

3. Abrams P, Cardozol L, Fall M, et al. The standardization of terminology of lower urinary tract function. Report from the standardization sub-committee of the international continence society. Neurourol Urodyn, 2002;21:167-78.

4. Minassian VA, Drutz HP, Al-Badr A. Urinary incontinence as a worldwide problem. Int $\mathrm{J}$ Gynecol Obstet, 2003;82:327-338.

5. Peyrat L, Haillot O, Bruyere F, Boutin JM, Bertrand P, Lanson Y. Prevalence \& Risk factors of Urinary Incontinence in Young \& Middle Aged Women. BJU Int. 2002;89(I):61-6.

6. Versi E, Defever M, Hu TW, et al. Socioeconomic considerations in urinary incontinence. In: Abrams P, Khoury S, Wein A. Incontinence. Report of the World Health Organization Consensus Conference. Plymouth, UK: Health Publications Ltd., 1999, pp. 869-929.

7. Yan-feng $S$, Wen-ju Z, Jian $S$ and Bo X. Prevalence and risk factors of urinary incontinence in Fuzhou Chinese women. Chinese Medical Journal. 2005;118(11):887892.

8. Samuelsson E, Victor A, Tibblin G. A population study of urinary incontinence and nocturia among women aged 20-59 years. Prevalence, 
well-being and wish for treatment. Acta Obstet Gynecol Scand. 1997;76:74-80.

9. Sandvik H, Hunskaar S, Vanvik A, et al. Diagnostic classification of female urinary incontinence: an epidemiological survey corrected for validity. J Clin Epidemiol. 1995;48:339-343.

10. Joao L. Amaro, Carlos A. Macharelli, Hamilto Yamamoto, Paulo R. Kawano, Carlos R. Padovani, Aparecido D. Agostinho Prevalence and Risk Factors for Urinary and Fecal Incontinence in Brazilian Women International Braz J Urol 2009; 35 (5): 592-598.

11. Lasserre A, Pelat C, Gueroult V, Hanslik T, Chartier-Kastler E, Blanchon T, Ciofu C,
Montefiore ED, Alvarez PF, Bloch J, Urinary Incontinence in French Women: Prevalence, Risk Factors, and Impact on Quality of Life. Europe a neurology 2009; 3007; 7.

12. El-Azab AS, Mohamed EM, and Sabra HI, The Prevalence and Risk Factors of Urinary Incontinence and Its Influence on the Quality of Life Among Egyptian Women Neurourology and Urodynamics 2007; 26:783-788.

13. Yan-feng $S$, Wen-ju $Z$, Jian $S$ and Bo $X$. Prevalence and risk factors of urinary incontinence in Fuzhou Chinese women. Chinese Medical Journal. 2005;118(11): 887-892. 